\title{
ANALYSIS OF THE PSICOMETRIC PROPERTIES OF A MULTIPLICATION AND DIVISION PROCESSES ASSESSMENT SCALE
}

\author{
Yazna Cisternas Rojas \\ Pontificia Universidad Católica de Valparaiso (Chile) \\ $\mathrm{M}^{\mathrm{a}}$ Dolores Gil Llario \\ Department of Developmental and Educational Psychology. University of València (Spain) \\ dolores.gil@uv.es \\ Roberta Ceccato \\ International University of Valencia (VIU) (Spain) \\ roberta.ceccato@campusviu.es \\ M $^{\mathrm{a}}$ Isabel Marí-Sanmillán \\ Department of Education Sciences. \\ CEU Cardenal Herrera University. Castellón \\ maria.mari1@uchceu.es
}

Fecha de Recepción: 10 Enero 2019

Fecha de Admisión: 30 Abril 2019

\begin{abstract}
The domain of multiplication and division operations depends on both algorithm management and the ability to identify the semantic structure of the problem and to translate it into mathematical language. Many students present difficulties in identifying the semantic structure of the problem but not applying the algorithm when the problem is presented numericaly. The aim of the study is to validate an assessment tool of the processes involved in multiplication and division problems solving in order to identify the causes of mistakes. The administration to 368 ten-to-twelve yearsold children highlighted a three-factor structure of the test: a factor composed of tasks that require just the domain of the algorithm, a second one that demand the identification of the operation, and a third one requiring both processes. The reliability of the instrument has been satisfactory and a qualitative analysis of the responses to the error detection and correction is proposed.

Keywords: multiplication; division; algorithm; mistakes; word problem

INTRODUCTION

Math skills involve a wide range of skills and cognitive processes some of which appear already among very young people like discrimination of quantities or the using of small numbers (Dehaene, 2001; Wynn, 1992). This phenomenon has been interpreted as evidence that the human brain is born with an innate sense of numbers, on which gradually settle the remaining skills that make mathematical competence (Grabner \& Schneider, 2009). In this, Pope (2012) emphasized that the
\end{abstract}


connection between mathematical operations is fundamental, highlighted that children are unlikely to be successful in algorithms such as division if they don't have a good understanding of the concepts underlying multiplication skills. Therefore those two operations, multiplication and division, have been the focus of interest for improving student math performance (Ding, Li \& Capraro, 2013; Nelson \& Harwood, 2011; Watson, 2012). But the mastery of these operations entails difficulties and it is essential to identify which errors students tend to do when they face solving multiplication or division (Isoda \& Olfos, 2011; Oliva Rodriguez, Enesco Jimenez \& Dopico, 2008; Villarroel, 2012).

For getting over the multiplication and division operations not just specifying the domain of the algorithm is required but also identifying the suitability or not of its implementation in order to reach the required understanding to know when it is correct to use the operation or not. This requires to identify the semantic structure of the problem and to be able to translate verbal language into mathematical language.

Often in mathematics persistent errors occur and they can cause serious problems if they are not resolved in the educational path of students (Ayyildiz \& Altun, 2013; Biber, Tuna \& Korkmaz, 2013; Cueli, García \& González-Castro, 2013; González-Pienda \& others, 2012; McGuire, Kinzie \& Berch, 2012). Therefore the understanding and use of effective strategies that would help students avoiding mistakes is one of the most important aspects in educational practice. It is necessary to identify the processes that are not adequately developing to diagnose the specific difficulty involved and be able to intervene in order to prevent further problems that can occur when errors are consolidated (Burton, 2010; Cardenas, Blanco, Gomez \& Guerrero, 2012; Sözen \& Bolat, 2011).

Despite the importance that persistent errors have on the development of learning mathematical concepts, there are very few studies that focus on its analysis and evaluation. According to Melis (2004) the analysis of errors has been largely neglected in traditional teaching mathematics, since behavioral theory, whose influence still perceived in schools, does not allow us to see errors as an essential source of learning but considering that learning is better when there are correct answers and no errors, so that what is right is rewarded and what is wrong is penalized. However, although it is true that mistakes are undesirable, they can provide information about the processes that are being affected and it would be good that teachers could analyze the mistakes that their students tend to present in order to prevent persistent errors and to identify the key factors that can improve their mathematical competence (Ayyildiz \& Altun, 2013; Steinle, 2004).

On this point, there have been few studies aimed at detecting and evaluating all the processes involved in mathematical competence in multiplication and division. For those reasons, the objective of this study is to validate an assessment tool of the processes involved in problems solving of multiplication and division called Process Assessment Scale in Multiplication and Division (PROMUDI) in order to make available to researchers and teachers a reliable and standardized test to identify the quality of the processes involved as well as the major errors in multiplication and division.

\section{METHOD}

\section{PARTICIPANTS}

The study involved a total of 368 students in the fourth year of primary education belonging to thirteen schools in the public education network, commune of Quillota in the Fifth Region of Chile. 225 of all students were women, representing $61.1 \%$ of the sample, and 143 men (38.9\%). The age range was from 10 to 12 years old, with the average age of 10.9 years. The students' families had an average socioeconomic and cultural level. 


\section{Instrument}

The assessment tool of the processes involved in multiplication and division problems solving (PROMUDI) consists of 18 multiple choice items with four alternatives, each of whose refers to a common error (eg. Addition instead of multiplication) and evaluates the competence in multiplication and division. More specifically, the instrument allows knowing how students perform with different types of tasks and error patterns. For performance evaluation according to the task, the test consists in different types of items that are categorized depending on the format of the problem statement: Problems in text format that only require the identification of the operation to perform but not the calculation (items 1, 5, 13, 16); problems in text format that require the identification of the operation to perform and also its execution (items 2, 6, 10, 12, 14); problems in text format supported by graphical representation that require identification of the operation to be performed with and without executing it (items $3,4,8,9$ ) and finally, problems that require only the execution of the operation directly proposed in numerical form (items 7, 11, 15, 17 and 18). For complete instrument, request a copy to the authors.

\section{Procedure}

After obtaining the permits to each school's management team of the district and to the teacher of the corresponding classroom, each school was informed about the research objectives and associated requirements. Thus, at the beginning of the academic year, the PROMUDI scale was administrated to children in sessions lasting approximately 90 minutes in their own classroom during school hours.

\section{Data analysis}

To evaluate the psychometric properties of the instrument the following analysis were conducted: statistical analysis of the items (mean, standard deviation, asymmetry and kurtosis) and confirmatory factor analysis (CFA) using models of structural equation. Goodness indices used were: the absolute level Satorra-Bentler Chi-square and its ratio with degrees of freedom df, RMSEA parsimony index (Root Mean Square of Error aproximation) and comparative indices CFI (Comparative Fit Index; Bentler, 1990), NFI (Normed Fit Index; Bentler and Bonnet, 1980) and NNFI (No Normed Fit Index; Bentler and Bonnet, 1980). Finally the composite reliability IFC (Fornell and Larcker, 1981), the average variance extracted AVE (Fornell and Larcker, 1981) and the alpha of Cronbach (1951) were analyzed for each factor through the AFC confirmed. All statistical analyzes were performed with the IBM SPSS version 19 program and the EQS version 6.2.

\section{RESULTS}

First a statistical analysis of the items of the test was conducted. As shown in Table 1, the mean scores obtained in the different items range from .04 in item 18 and .94 in item 7. By looking at the items whose statement is presented in text format, the highest average score (.88) corresponds to item 2 and referred to solve the task performing a calculation and lowest score (.31) referred to item 13 involving only the identification of the operation to perform. Among the items whose statement also includes a graphical representation of the text support, the minimum and maximum score are respectively corresponding to the item $8(.32)$ and in item $3(.88)$. Finally, among the items represented in the statement of an arithmetic operation, the highest score (.94) it is the item 7 and item lowest one, the item $18(.04)$, both referred to the management of knowledge on operation's mathematical properties. 
Table 1. Metric properties of items that compose PROMUDI

\begin{tabular}{|c|c|c|c|c|c|c|}
\hline Ítem & Scale & Subscale & Average & SD & Asymmetry & Kurtosis \\
\hline 1 & Text & No calculation & .62 & .49 & -.49 & -1.76 \\
\hline 5 & Text & No calculation & .64 & .48 & -.56 & -1.68 \\
\hline 13 & Text & No calculation & .31 & .46 & -.84 & -1.30 \\
\hline 16 & Text & No calculation & .47 & .49 & .12 & -1.98 \\
\hline 2 & Text & With calcul. & .88 & .32 & -2.36 & 3.69 \\
\hline 6 & Text & With calcul. & .42 & .49 & .32 & -1.90 \\
\hline 10 & Text & With calcul. & .79 & .41 & -1.41 & -.01 \\
\hline 12 & Text & With calcul. & .63 & .47 & -.78 & -1.39 \\
\hline 14 & Text & With calcul. & .41 & .49 & -.36 & -1.87 \\
\hline 3 & Text+repres. & With calcul. & .88 & .33 & -2.31 & 3.32 \\
\hline 4 & Text+repres. & With calcul. & .58 & .49 & -.31 & -1.91 \\
\hline 8 & Text+repres. & With calcul. & .32 & .47 & .78 & -1.39 \\
\hline 9 & Text+repres. & No calculation & .80 & .40 & -1.53 & .35 \\
\hline 7 & Calculation & Properties & .94 & .24 & -3.61 & 11.07 \\
\hline 11 & Calculation & Properties & .53 & .49 & -.12 & -1.99 \\
\hline 15 & Calculation & Properties & .49 & .50 & .05 & -1.99 \\
\hline 17 & Calculation & Properties & .19 & .39 & 1.53 & .35 \\
\hline 18 & Calculation & Properties & .04 & .49 & .23 & -1.95 \\
\hline
\end{tabular}

Subsequently a confirmatory factor analysis was conducted (CFA). As shown in Table 2, the model tested with the student sample $(n=368)$ has a very good fit, since the absolute index SatorraBentler Chi-square is 195.53 with 132 degrees of freedom; the parsimony index RMSEA is .04 (<.05 good and fit, between .05 and .08 acceptable,> .08 poor ; Browne and Cudeck, 1993) and comparative indexes CFI, NFI and NNFI correspond respectively to 0.91 (90-95 acceptable,> $95 \mathrm{good}$, Hu and Bentler, 1999) .89 (> .90 good; Schumacker and Lomax, 1996) and .90 (> .90 good; Ulman, 2001). 
Tabla 2. Goodness of fit index of the CFA of the instrument PROMUDI

\begin{tabular}{lllllll}
\hline $\mathbf{X}^{2}$ s-B & $\mathbf{d f}$ & $\mathbf{X}^{2}$ s-B/df & NNFI/TLI & RMSEA & CFI & NFI \\
\hline 195.53 & 132 & 1.48 & .90 & .04 & .91 & .89 \\
\hline
\end{tabular}

Figure 1 shows the model drawing of the CFA developed with the items of PROMUDI instrument. As shown in the drawing (path diagram), the existence of 3 factors is confirmed: a first factor consisting of computational tasks and knowledge of the properties of the algorithm. This first factor was called "No text-calculate"; a second factor involving the processes of understanding the semantic structure of the problem and the identification of the operation, named "Text-identify operation"; and finally a third factor of items which require the completion of both the process of understanding the semantic structure of the problem (with or without graphics support), as well as identifying the operation to perform and conduct the relevant calculation. This third factor has been called "Text-calculate". Standardized model weights ranged from .11 and .16 for the first factor, between .11 and .92 for the second and between .10 and .99 for the third one (see Figure 1).

Figure 1. Drawing (path diagram) of the test PROMUDI

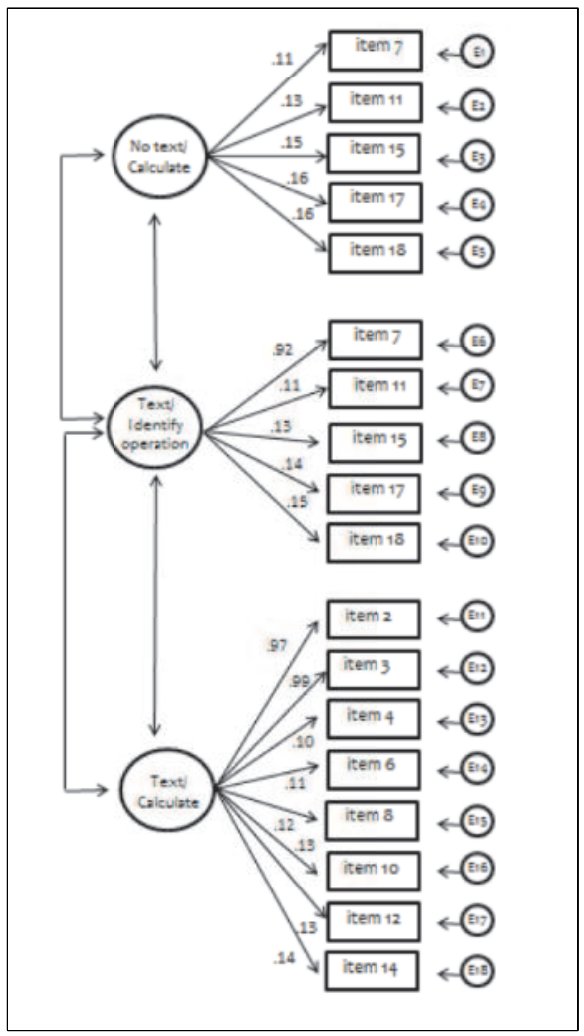


Next goal was to find out the reliability, validity and internal consistency of the test. An analysis of the composite reliability IFC (Fornell and Larcker, 1981), the Average Variance Extracted AVE (Fornell and Larcker, 1981) and the Cronbach (1951) for each factor confirmed through the CFA were developed. As we can see in Table 3, the obtained model has an acceptable Cronbach's alpha, being .41 for factor $1, .47$ for the second factor and .59 for the third one.

Analyzing the average variance extracted (AVE) it has been possible to highlight slightly lower values, being the AVE of the 3 factors respectively $.16, .18$ and .17 . However, the reliability composed index IFC whose interpretation is similar to the one used for Cronbach's alpha, proved to be satisfactory in all factors found. So, it is possible to say that the factor with most satisfactory score is the third one, as the IFC is .60. The values of the factors 1 and 2 are equally acceptable although slightly lower, with .43 and .50 respectively.

Table 3. Indexes PROMUDI reliability test.

\begin{tabular}{lccc}
\hline & IFC & AVE & Cronbach $\alpha$ \\
\hline Factor 1: No text calculate & .43 & .16 & .41 \\
Factor 2: Text-identify operation & .50 & .18 & .47 \\
Factor 3: Text-calculate & .60 & .17 & .59 \\
\hline
\end{tabular}

\section{DISCUSSION}

Knowing the specific performance of multiplication and division tasks is of fundamental importance for the analysis of learning and development of teaching mathematics in basic education since students tend to confuse arithmetic operations partly because of a low capacity to recognize the process to use and a lack of proper information processing (Ayyildiz \& Altun, 2013; Krawec, 2012; Montague, 2008).

Therefore, the understanding of which kind of tasks and errors students usually commit when facing problems involving multiplication and division is very important, in order to prevent its assimilation becoming strong and resistant to any type of intervention

In response, our research focused on the standardization and factorization of the PROMUDI test. Our analysis highlighted a structure of three factors that include the 18 items making up the test. A first factor groups the components of tasks that require only the execution of the algorithm; a second factor, meanwhile, collects the items that require the identification of the semantic structure of the problem with the choice of the correct operation required to solve the problem; and finally the third factor presents the items that involves both the understanding of the semantic structure of the problem and the implementation of the algorithm.

Thus, this study not only allows us to analyze the factorial structure of "PROMUDI" instrument and confirm its validity and reliability, but also ensures that we are facing an instrument that will recognize the specific performance tasks on multiplication and division for students in Primary Education. A second use of the instrument is the easy identification of the type of error commit by the student, performing a qualitative analysis of the referred responses. Actually, to evaluate pattern error by students, items present different alternative responses by proposing five situations: the student adds instead of multiply or divide, he/she subtracts instead of multiply or divide, he/she reverses the operation multiplying instead of dividing or vice versa, he/she does not know which operation to perform and, finally, despite correctly identify the operation he/she makes mistakes in the calculation. 
According to Ayyildiz \& Altun (2013) the objective to be pursued by a teacher, it is not to ignore the mistakes focusing only on the production of correct answers, but to detect them at an early stage avoiding, thus, the student to persist in error for long periods of time. In this context the development and validation of an instrument as PROMUDI allows teachers to early identify the processes that may be affected as well as the mistakes made by their students in order to improve the acquisition of mathematical competence in multiplication and division.

\section{BIBLIOGRAPHIC REFERENCES}

Ayyildiz, N. \& Altun, S. (2013). An Investigacion of the effect of learning logs on remedying students' misconceptions concerning mathematics lesson. H.U. Journal of education, 28 (2), 71-86.

Biber, C., Tuna, A. \& Korkmaz, S. (2013). The mistakes and the misconceptions of the eigth grade students on the subject of angles. European Journal of Science and Mathematics Education, 1 (2), 50-59.

Burton, M. (2010). Five strategies for creating meaningful mathematics experiences in the primary years. YC Young Children, 65 (6), 92-96.

Cárdenas, J., Blanco, L., Gómez, R. \& Guerrero, E. (2012). Resolución de Problemas de Matemática y Evaluación: Aspectos afectivos y cognitivos. En V. Mellado, L. Blanco, A. Borrachero, \& J. Cárdenas, Las Emociones en la Enseñanza y Aprendizaje de las Ciencias y las Matemáticas, 6788. Badajoz: DEPROFE.

Cueli, M., García, T. \& González-Castro, P. (2013). Autorregulación y rendimiento académico en Matemáticas. Aula Abierta, 41 (1), 39-48.

Dehaene, S. (2001). Precis of "the number sense." Mind and Language, 16, 16-32.

Ding, M., Li, X. \& Capraro, M. (2013). Preservice elementary teachers knowledge for teaching the associative property of multiplication: a preliminary analysis. Journal of Mathematical Behavior. 32, 36-52.

González-Pienda, J., Fernández, S., Suarez, N., María, F., Tuero, E., García, T. \& de Silva, E. (2012). Diferencias de género en actitudes hacia las matemáticas en la enseñanza obligatoria. Revista Iberoamericana de Psicología y Salud, 3(1), 55-73.

Isoda, M. \& Olfos, R. (2011). Enseñanza de la multiplicación: Desde el estudio de Clases japonés a las propuestas Iberoamericanas. Valparaíso: Ediciones Universitarias de Valparaíso.

Krawec, J. (2012). Problem Representation and Mathematical Problem Solving of Students of Varying Math Ability. Journal of Disabilities, Published online before print March 5, 2012.

Mc Guire, P., Kinzie, M. \& Berch, D. (2012). Developing number, sense in Pre-K with five-frames. Early Childhood Educ J, 40, 213-222.

Melis, E. (2004). Erroneous examples as a source of learning in mathematics ejemplos. Cognición y Aprendizaje exploratorio en la Era Digital CELDA, 311-318.

Montague, M. (2008). Self-regulation strategies to improve mathematical problem solving for students with learning disabilities. Learning Disabilities Quarterly, 31, 38-44.

Nelson, J. \& Harwood, H. (2011). Learning disabilities and anxiety: A meta-analysis. Journal of learning disabilities, 44(1), 3-17.

Oliva, M., Rodríguez, P., Enesco, I., Jiménez, L. \& Dopico, C. (2008). Me sobran cuatro y no sé qué hacer con ellos. Un estudio sobre los problemas de división con resto en alumnos de $1^{\circ}$ de ESO. Anales de Psicología, 24(2), 201-212.

Pope, K. (2012). Misunderstanding Misconceptions. Science Scope, 12-15

Sbaragli, S. \& Santi, G. (2011). Teacher's choices as the cause of misconceptions in the learning the concept of angle. Jornal International de Estudios en Educación Matemática, 117-157. 
Schneider, M. \& Grabner, R. (2009). Mental Number Line, Number Line Estimation, and Mathematical Achievement: Their Interrelations in Grades 5 and 6. Journal of Educational Psychology, 101(2), 359-372

Sözen, M. \& Bolat, M. (2011). Determining the misconceptions of primary school students related. Procedia-Social and Behavorial Sciences, 1060-1066.

Steinle, V. (2004). Detection and remediation of decimal miconceptions. Towards excellence in mathematics, 460-478.

Villarroel, V. (2012). Errores y aciertos comunes de estudiantes chilenos en las preguntas de la Prueba Pisa 2009. Santiago: MINEDUC.

Watson, J. (2012). Preservice Mathematics Teachers Understanding of Sampling: Intuition or Mathematics. Mathematics Teacher Education and Development, 2, 121-135.

Wynn, K. (1992). Addition and subtraction by human infants. Nature, 358, 749-750. 